\title{
A EXTENSÃO AGRÍCOLA E AS "ESCOLAS NA MACHAMBA DO CAMPONÊS" EM MOÇAMBIQUE: O CASO DA PRODUÇÃO HORTÍCOLA NAS ZONAS VERDES DA CIDADE DE MAPUTO
}

SITOE, Tomás Adriano. Programa de Pós-Graduação em Desenvolvimento Rural - PGDR da Universidade

Federal do Rio Grande do Sul - UFRGS. Pesquisador do Centro de Estudos Socioeconômicos do Instituto de Investigação Agrária de Moçambique. E-mail: sitoetoms@yahoo.com.

\begin{abstract}
RESUMO
Uma amostra de 68 produtores representando igual número de famílias, escolhidos ao acaso nas Zonas Verdes da cidade de Maputo, em Moçambique, foi usada para estudar o efeito da diversificação hortícola e acesso à assistência técnica na renda familiar. Os resultados indicam que a renda dos produtores do sexo masculino é estatisticamente igual à dos produtores do sexo feminino. Por outro lado, no local o nível de diversificação hortícola ainda é baixo e a assistência técnica ainda não se traduz em efeitos significativos na renda dos produtores.
\end{abstract}

Palavras-chave: Renda hortícola; Assistência técnica; Diversificação produtiva.

\begin{abstract}
A sample survey of 68 farmers representing the same amount of households was created to study the impact of crop diversification and access to extension services on on-farm income of horticultural producers in Zonas verdes (Maputo-Mozambique). Results indicate that there was no significant difference between the income of male and female producers. On the other hand, the level of crop diversification is still low and the impact of extension assistance has not yet brought appreciable changes on farmers' income.
\end{abstract}

KEYwORDs: Horticultural income; Extension assistance; Crop diversification. 


\section{INTRODUÇÃO}

Em Moçambique, o desenvolvimento da agricultura é fundamental para a redução da pobreza no país. Mais de $80 \%$ da população é rural e depende da agricultura para a sua sobrevivência. Segundo dados oficiais, mais da metade da população moçambicana vive ainda em condições de pobreza absoluta ${ }^{1}$. No entanto, quando se analisa o desenvolvimento da agricultura em Moçambique se depara com problemas clássicos da política agrária: falta de acesso ao crédito, baixa produtividade agrícola, insuficiente cobertura dos serviços públicos de extensão, falta de incentivos dos agentes de extensão, etc.

De um total de 128 distritos do país, apenas 55 estão cobertos pelo serviço público de extensão agrícola. Segundo o Trabalho de Inquérito de Agrícola - TIA 2002-03², o número total de extensionistas dos serviços públicos é 485 , enquanto a rede de extensão das ONGs é composta por 350 extensionistas ${ }^{3}$. Por outro lado, o uso de insumos modernos e mecanização é bastante limitado. De um total de aproximadamente 5 milhões de pequenas explorações, apenas $11 \%$ usam irrigação e tração animal; 3,7\% utilizam fertilizantes; $6,7 \%$, pesticidas; $16 \%$ das explorações contratam mão de obra; e apenas $14 \%$ têm acesso aos serviços de extensão rural. O rendimento agrícola dos principais cultivos do setor familiar é bastante baixo, conforme ilustrado na Tabela 1.

Tabela 1 - Rendimento de principais cultivos em Moçambique.

\begin{tabular}{|c|c|}
\hline Cultivos & Rendimento (Toneladas/Ha) \\
\hline Milho & 0,90 \\
\hline Sorgo & 0,60 \\
\hline Mileto & 0,32 \\
\hline Arroz & 1,10 \\
\hline Feijões & 0,45 \\
\hline Amendoim & 0,50 \\
\hline Mandioca & 5,50 \\
\hline
\end{tabular}

Fonte: Minag, 2006; KDS, 2009.

\footnotetext{
${ }^{1}$ No país, até o momento, foram efetuadas duas avaliaçãoes da incidência da pobreza: (i) em 1996/97, no Plano de Ação para a Redução da Pobreza (Parpa) I, a pobreza foi definida como sendo a "incapacidade dos indivíduos de assegurar para si e seus dependentes um conjunto de condições mínimas para a sua subsistência e bem-estar, segundo as normas da sociedade". Em 2002/03, no Parpa II, a pobreza foi definida como sendo a "impossibilidade por incapacidade, ou por falta de oportunidade de indivíduos, famílias e comunidades de terem acesso a condições mínimas, segundo as normas básicas da sociedade"(GdM, 2006:8). Considera-se que alguém está em condições de pobreza absoluta quando sobrevive com menos de dois dólares por dia.

${ }^{2} \mathrm{O}$ TIA, designação do Trabalho de Inquérito Agrícola no país; é levado a cabo pelo Ministério da Agricultura e visa à recolha de informação sobre a produção agrícola (número e tipo de explorações, tipo e volume de produção, destinos da produção, etc.). O TIA é anual, enquanto os censos são realizados de dez em dez anos.

${ }^{3}$ Grosso modo se pode dizer que o país possui 850 extensionistas para um universo de cerca de 16 milhões de produtores/ camponeses, o que é extremamente baixo.
} 
A extensão rural pode ajudar os produtores a aumentarem a produtividade da sua agricultura, através da adoção de tecnologias melhoradas ${ }^{4}$. No entanto, as origens de uma mudança específica na produtividade são mais complexas e múltiplas do que é comumente apreciado. "O aumento da produtividade não é apenas devido à mudança técnica, mas sim a partir da inovação institucional, as melhorias no capital humano, bem como nas mudanças em termos de disponibilidade de capital: físico e biológico" (BONNEN, 1998, p. 271). Isso é especialmente válido porque o objetivo central do governo é a redução substancial dos níveis de pobreza absoluta, por meio de medidas que melhorem as capacidades e as oportunidades dos moçambicanos, em particular para os pobres (GdM, 2006). Por outro lado, no país, a "Revolução Verde" constitui o novo paradigma de desenvolvimento agrário.

O presente estudo se propõe analisar o efeito do acesso à extensão agrícola sobre a diversificação e a renda agrícolas. A diversificação agrícola é definida como uma estratégia que consiste na utilização de cultivos mais lucrativos em relação aos existentes, mudando as variedades e o sistema de cultivo, aumentando as exportações e a competitividade tanto nos mercados domésticos como os internacionais, protegendo o meio ambiente, e tornando o meio ambiente mais favorável à combinação da atividade agrícola, com a pecuária e a silvicultura (van Luat 2001 apud Dharmaziri, 2007). Isso envolve práticas culturais que são especificamente concebidas para espalhar o risco ou tirar vantagens de complementaridade entre cultivos, no seu uso de nutrientes, luz solar e outros recursos (ELLIS, 2000, p. 111).
Para Dharmaziri (2007), a diversificação agrícola pode ter duas características: a horizontal, que consiste em adicionar mais cultivos ao sistema existente, e a vertical, que consiste em combinar a atividade agrícola às outras atividades.

A definição mais frequente de intensificação agrícola é dada por Tiffen et al. (1994, p. 29) e refere-se ao uso de mais recursos (capital e trabalho) em uma determinada parcela de terra: aumento médio dos fatores de produção, trabalho e capital em pequenas explorações ou apenas na terra cultivada, ou na terra cultivada e pastos com a finalidade de aumentar o valor do produto final por hectare 5 .

A agricultura extensiva implica o uso de poucos recursos em combinação com grande quantidade de terra; a agricultura intensiva implica o uso de grande quantidade de recursos em combinação com pouca quantidade de terra, para produzir maior quantidade de produto por hectare. Por isso, dependendo da forma como se faz o uso efetivo dos recursos, a intensificação pode ou não coincidir com a diversificação. A tradicional via de intensificação envolve a especialização, em vez de diversificação. No entanto, existem várias formas de intensificar a produção sem necessariamente ser a especialização (ELLIS, 2000, p. 111).

Para Bonnen (1998), tanto a mudança institucional quanto a mudança técnica envolvem o capital humano. As ideias de desenvolvimento do capital humano são basicamente produto de Theodor Schultz e Adam Smith, e foram posteriormente aprofundadas por Amartya Sen ${ }^{6}$. Desenvolver o capital humano significa despertar os neurônios humanos para que o homem

\footnotetext{
${ }^{4} \mathrm{~A}$ extensão é um processo através do qual novos conhecimentos e ideias são introduzidos no meio rural de modo a induzir mudanças e melhorias da vida dos produtores. A sua importância fundamental pode ser mais bem compreendida se forem considerados os seus três elementos essenciais: o conhecimento, a comunicação e a família (FAO, 1992, p. 10-14).

${ }^{5}$ Increased average inputs of labour or capital on a smallholding, either on cultivated land alone, or on cultivated and grazing land, for the purpose of increasing the value of output per hectare.

${ }^{6}$ Sen recupera as origens da economia, como sendo lastreadas em duas vertentes: a ética e a engenharia. A ética remete a Aristóteles e vincula a economia às finalidades humanas. A engenharia remete Walras e Willian Petty e preocupa-se principalmente com a lógica, "e não com os fins últimos", com o que favorecia "o bem do homem", ou com a questão "como se deve viver" (DE OLIVEIRA, 2007).
} 
seja útil à sociedade. De acordo com Sen (1997), as conexões entre "acúmulo de capital humano" e expansão das "capacidades humanas" residem no seguinte: o acúmulo do capital humano se concentra nos seres humanos, através das habilidades e conhecimentos, assim como o esforço em enfrentar as possibilidades de produção. A expansão das capacidades humanas focaliza-se nas habilidades dos seres humanos de conduzirem a vida que eles têm razão de valorizar e fortalecer as suas escolhas substantivas (SEN, 1997:1959).

Para Sen (1997), embora exista uma ligação entre as duas perspectivas, elas diferem e a diferença reside nos meios e nos fins; a abordagem do capital humano se enquadra em uma perspectiva mais inclusiva das capacidades humanas que pode cobrir tanto as suas consequências diretas como indiretas:

"Por exemplo, se a educação torna uma pessoa mais eficiente na sua produção de mercadorias, então isso é claramente um fortalecimento do capital humano. Isso pode ser acréscimo ao valor da produção na economia, e também à renda da pessoa que foi educada. Mesmo tendo o mesmo nível de renda a pessoa educada pode beneficiar da educação através da facilidade de comunicarse, argumentação, fazer escolhas de maneira informada, e ser tomado seriamente por outras pessoas, etc. Portanto, os benefícios da educação vão além do seu papel no processo produtivo" (SEN, 1997, p. 1959).

Além da abordagem das capacitações, a extensão rural é ligada às abordagens participativas - em que o conhecimento é visto como sendo a chave para o empoderamento. Considera-se indispensável a combinação do conhecimento científico e conhecimento local. De acordo com Antholt (1998: 360), a iniciativa de política mais importante que se precisa é sair do foco primário de poder e responsabilidade na extensão para os clientes. A necessidade de "pôr os produtores primeiro lugar" (CHAMBERS, 1997). Para o autor, nas abordagens participativas um número de binários e oposições, tais como "os de cima" (uppers) e "os de baixo" (lowers), Norte e Sul, conhecimento profissional e conhecimento local são continuamente utilizados, como slogans de participação e empoderamento.

No entanto, o fato de que foco principal dessas abordagens se refira às pessoas consideradas como tendo pouco poder, ou marginalizadas, reproduz a ideia de que os centros sociais de poder e controle apenas se encontram ao nível macro ou central; desse modo, os que detêm o poder estariam localizados nas instituições de "cima", enquanto os que não detêm o poder estariam nos locais de "baixo"; isso reforça os argumentos a favor do empoderamento dos "de baixo" através da participação, pois seu conhecimento é pouco valorizado.

Nos anos 1960 e 1970, a extensão agrícola na África foi financiada por vários doadores por meio de programas de desenvolvimento rural e comunitário. De acordo comAntholt (1998:356), a maior avaliação da extensão nos países em desenvolvimento foi completada em 1994 pelo Banco Mundial, quando se constatou que a abordagem de cima para baixo para a transferência de tecnologias era sempre baseada em pacotes padronizados de recomendações, os quais não tinham em conta a heterogeneidade dos produtores. $\mathrm{O}$ conceito de Treinamento e Visita $(\mathrm{T} \& \mathrm{~V})$, que usa um produtor de contato como recipiente primário das visitas do extensionista (para uma posterior transferência da tecnologia a outros produtores), mostrou-se menos efetivo, e muitas vezes era substituído pelo método dos grupos de camponeses (ANTHOLT, 1998: 357).

De acordo com Cleaver (1993:76), essa experiência insatisfatória levou várias escolas de pensamento a considerar o que fazer em relação à extensão agrícola na África. O uso dos grupos de produtores parece ser o método promissor da extensão no século XXI.

No país, a abordagem de $T \& V$ foi introduzida em 1988, coincidindo como estabelecimento do Programa Nacional de Extensão; no entanto, essa abordagem vem sendo transformada desde 1992 para enfocar a ação da extensão nos grupos de produtores. Por 
exemplo, um extensionista trabalha diretamente com 10 a 16 grupos de 15 a 20 produtores. $\mathrm{O}$ novo paradigma enfatiza a necessidade de abordagem orientada de baixo para cima, a parceria com o setor privado, a desconcentração de serviços, em combinação com a provisão de serviços orientados pela demanda (Minag, 2006:21).

As "Escolas na Machamba do Camponês" - EMC são um "processo" baseado nos conceitos de educação não formal de adultos. "Esses conceitos se têm mostrado relevantes em vários países e culturas onde se tem usado a abordagem das Escolas na Machamba do Camponês" (BRAUN \& DUVESKOG, 2008, p. 8).

Para Dzeco et al. (2010), as "Escolas na Machamba do Camponês" foram criadas em vários países com o apoio das Nações Unidas, de acordo com o princípio maior de "envolver os camponeses na aprendizagem e descoberta, através da experimentação e troca de conhecimentos entre eles com os agentes de extensão e pesquisadores".

Para Scarborough et al. (1997), a "Escola na Machamba do Camponês" é um processo e não um fim (goal) e se rege por umconjunto de princípios:

- os camponeses é que escolhem o tema a ser estudado;

- os extensionistas são facilitadores e não professores;

- aprender fazendo e aprender a aprender são cruciais;

- os problemas levantados devem ser resolvidos;

- a tomada de decisão deve ser parte do processo de aprendizagem.

A abordagem da "Escola na Machamba do Camponês" é uma experiência encorajadora no Desenvolvimento de Tecnologia Participativa (DTP) para resolver o problema da fome e da subnutrição da população camponesa. Também aborda assuntos como: HIV/Aids, gênero, alfabetização, poupança e crédito, agroprocessamento, marketing, desenvolvimento rural integrado, etc. Sendo assim, as EMC têm-se mostrado não só um veículo para melhorar o sistema de produção, introduzindo tecnologias que possam ser adotadas pelos camponeses nas suas machambas individuais, mas também uma metodologia que fortalece a autoestima e a capacidade dos grupos de forma a trabalharem em coletivo de ajuda mútua para umfuturo melhor e melhorar o seu sustento (SINGH, 2007).

No entanto, embora as "Escolas na Machamba do Camponês" tenham uma grande aceitação no país, não existem ainda estudos para avaliar o seu impacto (DZECO et al., 2010, p. 117). Para Davis (2006, p. 92), apesar de ser popular, a maior parte dos escritos sobre a chamada nova ortodoxia - o método das "Escolas na Machamba do Camponês" -, encontrase em "literatura cinzenta", e trata da metodologia e estudos de caso.

Apesar disso, em uma escala global existem evidências convincentes de que as "Escolas na Machamba do Camponês" têm impacto na redução no uso de pesticidas, aumento de produtividade, e ganhos de conhecimentos entre os camponeses (BRAUN \& DUVESKOG, 2008, p. 19) e empoderamento (DZECO et al., 2010). No entanto, alguns estudos indicam que as EMC têm pouco ou mesmo nenhum efeito no desempenho econômico, ambiente, saúde e disseminação de informação e tecnologias entre os camponeses. Por outro lado, vários atores de desenvolvimento têmquestionado a sustentabilidade das "Escolas na Machamba do camponês" (BRAUN \& DUVESKOG, 2008, p. 19).

Para Braun \& Duveskog (2008), o empoderamento referido nas avaliações refere-se à elevação de autoestima e satisfação, mudança social e ação, atributos desenvolvidos após a participação na EMC: os produtores ganharam "agência" em termos de controle e orientação de suas vidas. No entanto, o problema é que a maior parte dos estudos tem um alcance limitado e foi conduzido em contextos de projetos (DAVIS, 2006, p. 92; BRAUN \& DUVESKOG, 2008, p. 19). Por outro lado, na medição dos impactos das "Escolas na Machamba do Camponês" não existe ainda concordância em termos do que medir, como medir, ou como avaliar os resultados das medições dos impactos.

Para Braun \& Duveskog (2008), a falta de consenso acontece em parte por causa da disputa 
sobre a classificação das EMC, se são um investimento na educação ou uma atividade de extensão, e se os impactos importantes se referem à mudança tecnológica ou à capacidade humana/social (BRAUN \& DUVESKOG, 2008, p. 19).

Para Davis (2006, p. 91), embora a abordagem seja agressivamente promovida pelos doadores, governos e ONGs, como a próxima melhor coisa na extensão, as evidências sugerem que a maior parte das questões inerentes ao modelo não está sendo tratada.

Portanto, é com base nas questões acima expostas que o presente estudo procura explorar a relação entre a diversificação produtiva e o acesso à extensão rural. As principais questões que se colocam são: (i) se os produtores que recebem assistência técnica têm relativamente maior renda; (ii) se existe diferenças de renda agrícola entre os produtores diversificados e os não diversificados.

\section{Metodologia}

A natureza dos objetivos estabelecidos requer a aplicação de métodos quantitativos em combinação com métodos qualitativos de investigação. Os dois métodos são usados concomitantemente, com a intenção de complementaridade entre eles. As conexões entre os dois componentes (qualitativo e quantitativo) são feitas na análise dos resultados, para trazer maior insight sobre a pesquisa. De acordo com O'Cathain \& Thomas (2009, p. 117), os métodos mistos originam um "valor agregado" nas pesquisas.

A compreensão das diferentes estratégias de sustento familiar pressupõe uma epistemologia construtivista e pragmática. De acordo com Creswell (2010), existem várias formas de pragmatismo; no entanto, para várias delas, em vez de condições antecedentes (como acontece com o pós-positivismo), o conhecimento sobressai das ações, situações e consequências.

A partir de uma amostra de 68 produtores escolhidos ao acaso realizaram-se dois tipos de entrevistas $^{8}$ :

1. Entrevistas semiestruturadas com informadores qualificados, compostos por 12 líderes de associações de produtores, que também são produtores de hortaliças; uma reunião organizada pela Direção Distrital da Agricultura das Mahotas foi realizada na sede dessa instituição e tinha dois propósitos: (i) fazer um levantamento inicial dos problemas e preocupações dos produtores em relação à atividade agrícola; e (ii) solicitar que esses líderes ajudassem a organizar encontros com produtores para aplicação do questionário. Um calendário de visita às associações de produtores que esses líderes representam foi estabelecido durante essa reunião. Ficou concordado que cada líder convocasse 10 produtores para serem entrevistados durante a visita à associação ${ }^{9}$.

2. Aplicação do questionário de perguntas semiestruturas aos 68 produtores selecionados aleatoriamente em 8 associações nos distritos 4 (Mahotas) e 5 (Vale do Infulene). Essas entrevistas visaram aprofundar o conhecimento em relação à informação colhida junto aos líderes das associações,

\footnotetext{
${ }^{8}$ Nos estudos rurais, como naqueles voltados à aplicação da abordagem dos modos de vida, Chambers (1997) enfatiza a necessidade de mudança de paradigma em relação aos métodos participativos. O Participatory Learning Action (PLA) constitui uma inovação em relação à técnica Rapid Rural Appraisal (RRA) por ele proposta em 1992. Fundamentalmente essa inovação foi orientada por duas razões: (i) a necessidade de mudança de atitude por parte dos pesquisadores e agentes de desenvolvimento, para que se coloque o "produtor primeiro". Mais do que se preocupar em recolher os dados, essa técnica enfatiza a necessidade de os beneficiários proporem as soluções dos seus problemas; (ii) o fato de que RRA também se aplicava em contextos urbanos. A filosofia subjacente à "Ação" nesta técnica está relacionada com a necessidade de transformação de fazer as pesquisas ou o desenvolvimento, de tal modo que esses processos sejam emancipatórios e tenham a finalidade de empoderar os potenciais beneficiários.

${ }^{9} \mathrm{Em}$ alguns casos não compareceram todas as pessoas convocadas ou não foram entrevistadas todas as pessoas que compareceram, porque as respostas quase que não variavam substancialmente.
} 
bem como colher dados que permitissem estimar a renda hortícola e de outras atividades fora da machamba no nível do agregado familiar. Através de perguntas abertas e em profundidade (perguntas baseadas no que a pessoa entrevistada diz), procurouse explorar vários aspectos da vida dos produtores, por exemplo: (i) como ganham o dinheiro, (ii) quais as redes de sociabilidade, (ii) quais os mecanismos de redistribuição (pensões de aposentadoria, invalidez, serviços sociais, etc.), bem como explorar se esses mecanismos eram mais importantes para um grupo particular de produtores ${ }^{10}$. Antes de aplicar o questionário, as entrevistas foram precedidas de uma reunião com os produtores na associação para explicar os objetivos da pesquisa e os procedimentos a seguir. A presença dos líderes no encontro não constituiu uma restrição em relação à abertura dos produtores; ao contrário, se percebeu que os líderes estimulavam os produtores a se abrirem e a colocar todas as suas preocupações. Esse fato mostra a expectativa dos produtores em relação às ajudas: os produtores consideram importantes as visitas às associações, pois pensam que a partir delas podem canalizar as suas preocupações ao governo, daí a abertura nas reuniões. Dos 68 produtores entrevistados, 44 são das Mahotas e 24, do Vale do Infulene. No Infulene se decidiu terminar com esse número, uma vez que se constatou que as respostas dos produtores não diferiam muito.

Na ausência de uma contabilidade da atividade agrícola por parte dos produtores, procurou-se estimar a Margem Bruta Financeira (aqui designada renda hortícola) através da seguinte metodologia: a cada produtor entrevistado se procurou saber os cultivos praticados, bem como o número de canteiros produzidos por ano, e a frequência com que em média os cultivos são praticados por ano; por exemplo, a alface (em média) se produz até seis vezes ao ano, a couve até três vezes, o repolho até duas vezes, o feijão verde até duas vezes. A renda hortícola foi estimada por meio da multiplicação do número de canteiros produzidos pelo preço de médio de venda do canteiro, subtraindo os custos de produção (principalmente os gastos que o produtor realizou para aquisição de sementes, pesticidas e pagamento de mão de obra ${ }^{11}$ ).

Os resultados do questionário foram processados pelo software Statistiscs Program System for the Social Science - SPSS. Através desse programa foram processados e analisados principalmente os elementos de estatística descritiva. Além da análise quantitativa, o exame da compreensão subjetiva do sentido que os produtores dão à sua vida requereu, além da observação do comportamento e interpretação dos significados, a análise da sua fala e ação - elementos essenciais na análise qualitativa.

\section{Resultados E ANÁLISE}

A amostra de estudo foi composta de 68 produtores selecionados ao acaso, dos quais 44 (cerca de 65\%) pertencem às Mahotas e 24 (cerca de $35 \%$ ), ao Vale de Infulene. Nessa amostra, metade dos produtores entrevistados eram do sexo masculino e a outra metade, do sexo feminino. No entanto, nas Mahotas, onde a amostra foi relativamente maior, a proporção de homens para mulheres foi 25:19, enquanto no Vale de Infulene essa proporção foi 3:5 (Tabela 2).

\footnotetext{
${ }^{10}$ Este artigo se enquadra em uma pesquisa maior do trabalho de tese de doutorado do autor, cujo título é "Diversificação produtiva e de atividades de geração de renda: uma análise da produção hortícola na cintura verde de Maputo", e analisa não só a questão da assistência técnica, mas também questões como o acesso ao crédito, à terra, e a estratégia do governo para intensificação agrícola (a "Revolução Verde"); detalhes sobre a tese podem ser consultados na página HTTP://www.ufrgs.br/ pgdr.

${ }^{11}$ Os gastos com mão de obra apenas incluíram o pagamento de mão de obra contratada pelo produtor, quer sob a forma de empregado(s) permanentes ou trabalhadores eventuais, que no local praticam xitokos (trabalho por empreitada/biscate).
} 
Tabela 2 - Número e percentagem de homens e mulheres entrevistados, por região.

\begin{tabular}{|c|c|c|c|c|c|c|}
\hline$\overline{\text { Local }}$ & Homens & $\begin{array}{c}\text { Percentagem } \\
(\%)\end{array}$ & Mulheres & $\begin{array}{c}\text { Percentagem } \\
(\%)\end{array}$ & Total & $\begin{array}{c}\text { Percentagem } \\
\text { Total }(\%)\end{array}$ \\
\hline Mahotas & 25 & 73,53 & 19 & 55,88 & 44 & 64,71 \\
\hline Vale do Infulene & 9 & 26,47 & 15 & 44,12 & 24 & 35,29 \\
\hline Total & 34 & 100,00 & 34 & 100,00 & 68 & 100,00 \\
\hline
\end{tabular}

Fonte: Dados de pesquisa.

A renda hortícola média dos produtores é de 53.061,29 Meticais por ano ${ }^{12}$. Arenda dos produtores do sexo masculino é cerca de 67.000 Meticais e a renda média dos produtores do sexo feminino é cerca de 40.000 Meticais (Tabela 3). O teste estatístico realizado para comparar essas médias (Anova) mostra que o valor de Fé 3,471 e o nível de significância é 0,067 , maior que 0,050 (Tabela 4). Portanto, a $5 \%$ de probabilidade as diferenças entre esses valores não são significativas, sendo significativas a partir de 6\% (Tabelas 3 e 4 ). As diferenças de renda hortícola explicadas pelo sexo são de aproximadamente 5\% (Tabela 5).

Tabela 3 - Renda média hortícola por sexo dos produtores.

\begin{tabular}{lccc}
\hline Sexo & Média & Número & Desvio Padrão \\
\hline Masculino & $66.710,15$ & 34 & 60778,011 \\
Feminino & $39.412,44$ & 34 & 60037,047 \\
Total & $53.061,29$ & 68 & 61512,703 \\
\hline
\end{tabular}

Fonte: Dados de pesquisa.

\footnotetext{
${ }^{12} 1$ USD é aproximadamente igual a 34,00 Meticais.
} 
Tabela 4 - Análise de Variância (Anova) entre a renda hortícola dos produtores do sexo masculino e renda hortícola dos produtores do sexo feminino.

\begin{tabular}{lcclccc}
\hline & $\begin{array}{l}\text { Suma dos } \\
\text { quadrados }\end{array}$ & $\begin{array}{l}\text { Graus de } \\
\text { liberdade }\end{array}$ & $\begin{array}{l}\text { Quadrado } \\
\text { médio }\end{array}$ & F & $\begin{array}{l}\text { Nível } \\
\text { Significância }\end{array}$ & de \\
\hline Entre grupos & $1 \mathrm{E}+010$ & 1 & $1,27 \mathrm{E}+010$ & 3,471 & 0,067 \\
Dentro dos grupos & $2 \mathrm{E}+011$ & 66 & 3649206802 & & \\
Total & $3 \mathrm{E}+011$ & 67 & & & \\
\hline
\end{tabular}

Fonte: Dados de pesquisa

Tabela 5 - Medidas de associação entre a renda hortícola e o sexo dos produtores.

\begin{tabular}{lcc}
\hline & Eta & Eta Squared \\
\hline Renda hortícola * Sexo & 0,224 & 0,050 \\
\hline
\end{tabular}

Fonte: Dados de pesquisa

Nota: Eta como um coeficiente de correlação, indica a relação que existe entre a variável dependente e a variável independente; numa escala de 0-1, indica quanto de variância na variável dependente é ocasionada pela variável independente. O "Eta Quadrado" indica o percentual de variância na variável dependente que é explicada pela variável independente nos dados da amostra.

No entanto, o fato de que a renda dos homens não seja diferente da renda das mulheres não significa que não haja relações de trabalho diferenciadas em função do sexo. Até porque os dois valores são bem distintos, fato que é justificado pela distribuição assimétrica da renda dentro dos grupos. No local se observou que dentro da família há uma divisão social do trabalho de acordo com o gênero e idade. Por exemplo, nas machambas, a lavoura que constitui o trabalho mais pesado geralmente é efetuada pelo homem, enquanto as vendas nos mercados são tarefa exclusiva das mulheres. Convém salientar que o gênero é uma construção social dos papéis entre o homeme a mulher, e como tal esses papéis socialmente construídos envolvem geralmente desigualdade na distribuição de poder, tomada de decisão, controle de recursos, etc.
Por isso o gênero é fundamentalmente concernente ao poder, subordinação e desigualdade, e por causa disso, é também concernente às formas de mudar esses elementos no sentido de conferir maior igualdade entre a mulher e o homem (ELLIS, 2000, p. 139).

Por outro lado, alguns estudos no país indicam que a questão da pobreza é "feminizada": os agregados familiares chefiados por homens têm conseguido uma redução da pobreza muito superior que os chefiados por mulheres, e essa tendência estaria parcialmente relacionada com o fato de as mulheres estarem mais fortemente no setor agrícola, onde praticam uma agricultura de subsistência com baixa produção (TVEDTEN et al., 2008); por isso, Amartya Sen (2000, p. 35) considera que a renda às vezes revela muito pouco sobre o fenômeno da desigualdade entre 
os sexos. Até porque o sistema patrilinear dominante no Sulde Moçambique tem impactos em três aspectos: (i) no padrão de residência das famílias, isto é, quando a mulher se casa ela é que vai morar na casa do marido e não o contrário, como acontece no Norte, onde o sistema é matrilinear; (ii) no sistema de sucessão e herança (que dá os principais direitos à família do marido e às crianças, à custa da esposa e da família dela); e (iii) na posição do homem dentro do agregado familiar, que em princípio lhe confere todas as decisões importantes e direitos ampliados sobre a sua mulher, filhos e propriedade (ROSÁRIO et al., 2009).

No entanto, nas Zonas Verdes a participação dos homens na atividade agrícola é interpretada como sendo causada pela falta de empregos, conforme a afirmação seguinte:

Em algumas associações é relativamente maior o número de homens que o das mulheres; por exemplo, em duas associações aqui nas Mahotas temos mais homens que mulheres... O que fazer? Não há emprego; por isso, temos homens nas nossas machambas (Entrevista 1, Mahotas, 18/11/2009).

A aparente igualdade de renda entre os homens e as mulheres sugere que as estratégias para a promoção da produção agrícola não deveriam ser segregadas pela divisão biológica dos sexos; até porque, na África austral, embora as habilidades da mulher em responder às novas tecnologias - como, por exemplo, as novas práticas de cultivo - sejam limitadas pelas assimetrias de gênero, direcionar atenção ao apoio da mulher, como forma de aumentar a produção, é mais complicado do que a simples provisão de serviços à mulher (ELLIS, 2000, p. 148). No entanto, é importante realçar que os produtores mais pobres eram mulheres viúvas, portadoras de alguma doença, ou que não tinham terra própria. Isso significa que as ações para a promoção do desenvolvimento da atividade agrícola e inclusão social deveriam ter em conta esse grupo de produtores "mais pobres".

Dos 68 entrevistados, 66 pertencem às "pequenas machambas" e 2 às "quintas". Todas as "quintas" foram registradas no Vale do Infulene (Tabela 6).

Tabela 6 - Tipo de machamba por região de estudo.

\begin{tabular}{lcc}
\hline Local & \multicolumn{2}{c}{ Tipo de Machamba } \\
& Pequena machamba & Quinta \\
\hline Mahotas & 44 & 0 \\
Vale do Infulene & 22 & 2 \\
Total & 66 & 2 \\
\hline
\end{tabular}

Fonte: Dados de pesquisa

A relativa ausência de "quintas" nas Mahotas reflete não só a heterogeneidade da agricultura familiar nas Zonas Verdes, mas também, e mais importante a fraca vinculação dos proprietários das "quintas" nas associações de produtores, que é onde o estudo incidiu. A renda hortícola média dos produtores das "quintas" é de cerca de 327.000 Meticais, sete vezes maior que a renda hortícola média dos produtores das "pequenas machambas" (Tabela 7). 
Tabela 7 - Renda hortícola das pequenas machambas versus a das quintas nas Zonas Verdes da Cidade de Maputo.

\begin{tabular}{lcc}
\hline & Tipo de Machamba & Número \\
\hline & & 66 \\
Pequena machamba & $44.759,14$ & 2 \\
Quinta & $327.032,50$ & \\
Total & & 68 \\
\hline
\end{tabular}

Fonte: Dados de pesquisa

As Direções Distritais de Agricultura trabalham mais comos produtores das associações do que comos privados das quintas. Por seu turno, os técnicos de extensão rural consideram que dão mais apoio às associações para permitir que os pequenos produtores também cresçam e tenham sua autonomia, conforme sugere a afirmação seguinte:

"O Estado apoia mais as associações para que os pequenos produtores cresçam e tenham sua autonomia como os privados" (Técnico de extensão agrícola na Direção Distrital da Agricultura das Mahotas).

A diversidade de cultivos praticados é representada na Figura 1. Os principais cultivos incluem: couve $(99 \%$ dos entrevistados afirmaram ter produzido), alface (94\%), repolho (44\%), cenoura $(22 \%)$, beterraba e feijão verde (21\%), e abóbora (18\%).

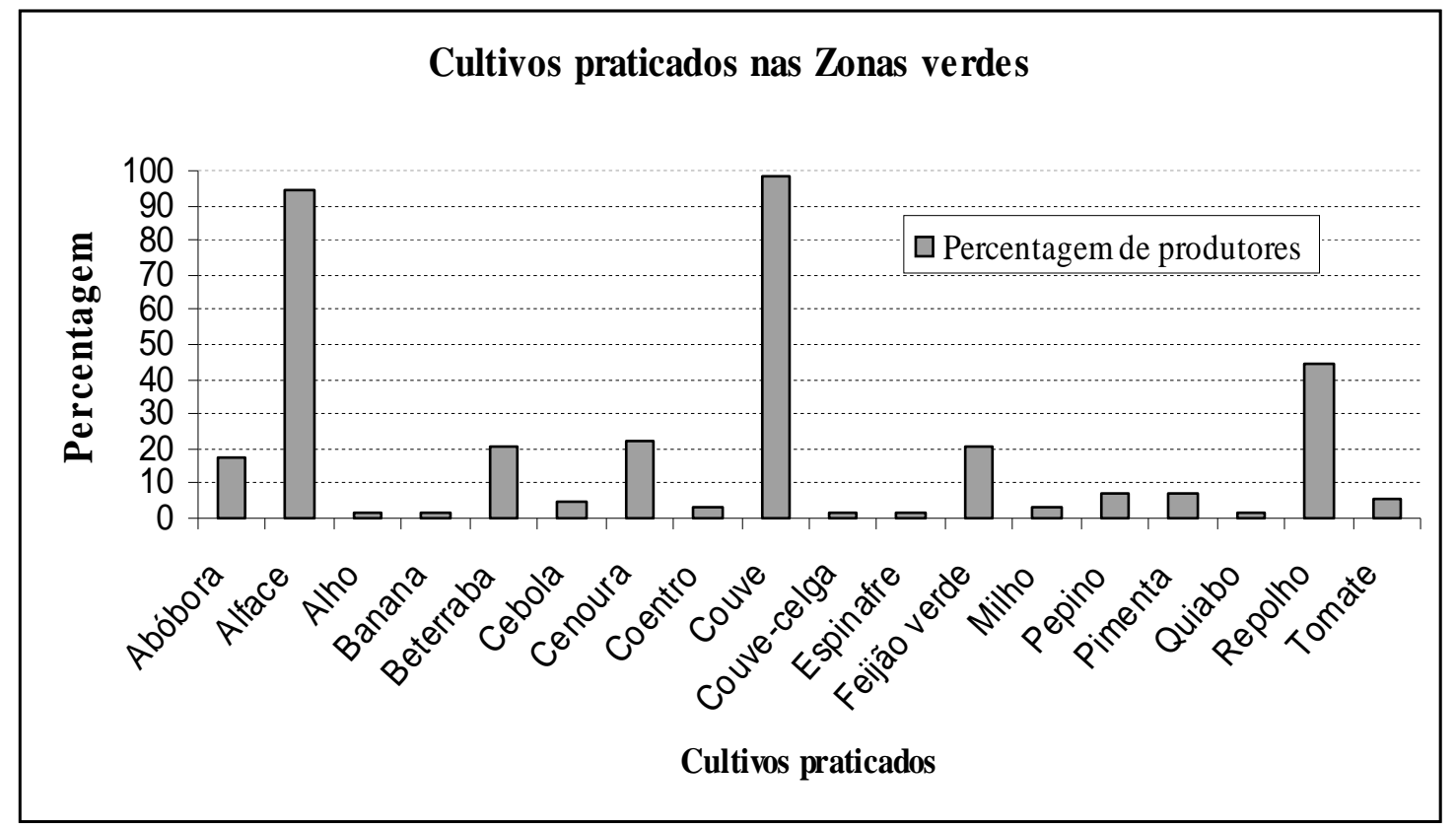

Figura 1 - Percentagem de produtores por cultivos praticados nas Zonas Verdes.

Fonte: Dados de pesquisa. 
A distribuição de cultivos praticados por região mostra maior diversidade de cultivos nas Mahotas do que no Vale do Infulene, onde os principais produtos são: couve e alface (todos os produtores dessa região cultivam), feijão verde (38\%) $)^{13}$, e abóbora (cultivada pela metade dos produtores) (Tabela 8$)$.

Tabela 8 - Cultivos praticados por região e número de produtores nas Zonas Verdes.

\begin{tabular}{lcc}
\hline Local/cultivo & Mahotas & Vale do Infulene \\
\hline Abóbora & 0 & 12 \\
Alface & 40 & 24 \\
Alho & 1 & 0 \\
Banana & 1 & 0 \\
Beterraba & 8 & 6 \\
Cebola & 3 & 0 \\
Cenoura & 10 & 5 \\
Coentro & 2 & 0 \\
Couve & 43 & 24 \\
Couve-celga & 1 & 0 \\
Espinafre & 1 & 0 \\
Feijão verde & 5 & 9 \\
Milho & 2 & 0 \\
Pepino & 4 & 1 \\
Pimenta & 5 & 0 \\
Quiabo & 1 & 0 \\
Repolho & 30 & 0 \\
Tomate & 4 & 0 \\
\hline
\end{tabular}

Fonte: Dados de pesquisa.

Os produtores que diversificaram a produção hortícola têm uma renda média de cerca de 61.000,00 Meticais. A renda hortícola média dos produtores que não diversificaramé de cerca de 27.000 Meticais. Em cada grupo de produtores (diversificados e não diversificados), a amplitude entre o valor máximo e mínimo é maior. $\mathrm{O}$ teste estatístico realizado (Anova) mostra que a estatística F é 3,788 e o nível de significação, 0,056. Portanto, as médias não diferementre os 2 grupos a $5 \%$ de significância, mas já passam a diferir a 5,6\% ou mais, o que sugere que a diversificação produtiva tem pouco efeito sobre a renda agrícola (Tabelas 9 e 10). As médias de renda entre os produtores diversificados e não diversificados são bem distintas; no entanto, as diferenças entre essas médias não são significativas a $5 \%$, porque há uma expressiva variabilidade dos valores de renda entre os grupos. Amaior variabilidade de renda hortícola mostra que nas Zonas verdes existem produtores com distintas capacidades em termos de geração de renda; no entanto, é importante realçar que a maior parte dos produtores está abaixo da renda média.

A percentagem de variação de renda explicada pela diversificação é de cerca de 5\% das variações na renda hortícola (Tabela 11).

${ }^{13} \mathrm{O}$ tipo de feijão verde que comumente é cultivado no Vale do Infulene se chama nhangana; o nome científico desse cultivo é Vigna unguiculta. 
Tabela 9 - Diversificação agrícola, médias de renda hortícola entre produtores diversificados e não diversificados nas Zonas Verdes.

\begin{tabular}{lccccc}
\hline Diversificou a produção & Média & Número & Desvio Padrão & Mínimo & Máximo \\
\hline \multirow{2}{*}{ Sim } & & & & & \\
& $60.951,69$ & 52 & 67633,81413 & 8250 & 358750 \\
Não & $27.417,50$ & 16 & 20761,13894 & 8800 & 79310 \\
& & & & & \\
Total & $53.061,29$ & 68 & 61512,70341 & 8250 & 358750 \\
\hline
\end{tabular}

Fonte: Dados de pesquisa.

Tabela 10 - Análise de Variância (Anova) entre a renda hortícola dos produtores diversificados e os não diversificados nas Zonas Verdes.

\begin{tabular}{lcclcc}
\hline & $\begin{array}{l}\text { Soma dos } \\
\text { quadrados }\end{array}$ & $\begin{array}{l}\text { Graus de } \\
\text { liberdade }\end{array}$ & $\begin{array}{l}\text { Quadrado } \\
\text { médio }\end{array}$ & F & $\begin{array}{l}\text { Nível de } \\
\text { Significância }\end{array}$ \\
\hline Entre grupos & $1 \mathrm{E}+010$ & 1 & $1,37 \mathrm{E}+010$ & 3,788 & 0,056 \\
Dentro dos grupos & $2 \mathrm{E}+011$ & 66 & 3632671922 & & \\
Total & $3 \mathrm{E}+011$ & 67 & & & \\
\hline
\end{tabular}

Fonte: Dados de pesquisa.

Tabela 11 - Medidas de associação entre a diversificação produtiva e a renda hortícola nas Zonas Verdes.

\begin{tabular}{lcc} 
& Eta & Eta Squared \\
\hline $\begin{array}{l}\text { Valor da renda hortícola * Diversificou a } \\
\text { produção }\end{array}$ & 0,233 & 0,054 \\
& & \\
\hline
\end{tabular}

Fonte: Dados de pesquisa.

A opinião dos produtores enquanto àimportância da diversificação produtiva é positiva; cerca de $80 \%$ dos entrevistados consideramimportantediversificar a produção, pois poderiam aumentar a sua renda (Tabela 12). 
Tabela 12 - Opinião dos produtores sobre a diversificação produtiva nas Zonas Verdes da Cidade de Maputo.

\begin{tabular}{lccc}
\hline \multicolumn{1}{c}{$\begin{array}{c}\text { Opinião dos } \\
\text { produtores }\end{array}$} & Frequência & Percentagem (\%) & $\begin{array}{c}\text { Percentagem } \\
\text { acumulada }(\%)\end{array}$ \\
\hline Muito importante & 4 & 5,9 & 5,9 \\
$\begin{array}{l}\text { Importante } \\
\text { Moderadamente }\end{array}$ & 54 & 79,4 & 85,3 \\
$\begin{array}{l}\text { importante } \\
\text { Menos importante }\end{array}$ & 10 & 14,7 & 100,0 \\
Total & 68 & 0 & 0 \\
\hline
\end{tabular}

Fonte: Dados de pesquisa.

A importância da diversificação também se percebe na resposta dos produtores quanto à pergunta sobre $\mathrm{o}$ que tinham semeado nas suas machambas. A esta pergunta enumeravamuma série de cultivos, alguns dos quais não tinham praticado naquele período/ano, o que sugere que conhecem outros cultivos diferentes dos que tinham nas suas machambas. Mais importante ainda é o fato de que a resposta era dada no plural: "plantamos couve, alface, repolho, cebola, etc.", o que sugere não só que a terra é apta para o plantio de diversos cultivos, mas também que atribuemum sentido coletivo à importância da diversificação. Apesar disso, na resposta dada no plural se percebeu que estariam dispostos a diversificar se houvesse algum apoio, principalmente por parte do Estado; é como se dissessem: se o senhor (eu, o pesquisador) trouxer um projeto de diversificação, eles (os produtores) estão em condições de executá-lo.
O nível de diversificação ${ }^{14}$ - uma medida da intensidade de diversificação produtiva - éainda baixo: embora a maior parte dos produtores tenha diversificado a sua produção, há ainda um número considerável de produtores cujo nível de diversificação é baixo ou que não diversificaram - metade dos produtores da amostra está nessas duas categorias (0 e 1) (Tabela 13).

Nas duas regiões (Mahotas e Vale do Infulene), embora não se tenha registrado diferenças em termos de percentagem de produtores que não diversificaram a sua produção, no Vale do Infulene dos 24 produtores entrevistados apenas 1 teve um nível alto de diversificação, isto é, praticou cinco ou mais cultivos; nas Mahotas, 12 produtores (cerca de 27\%) atingiram esse nível, o que reforça a observação de que as duas regiões são diferentes em termos de diversificação produtiva (Tabela 13).

${ }^{14}$ No presente estudo a diversificação da produção agrícola significa produzir diferentes tipos de cultivos, principalmente além daqueles cultivos que são mais comuns no local (a couve e alface); convencionou-se a classificar os diferentes níveis de diversificação em função dos seguintes critérios:

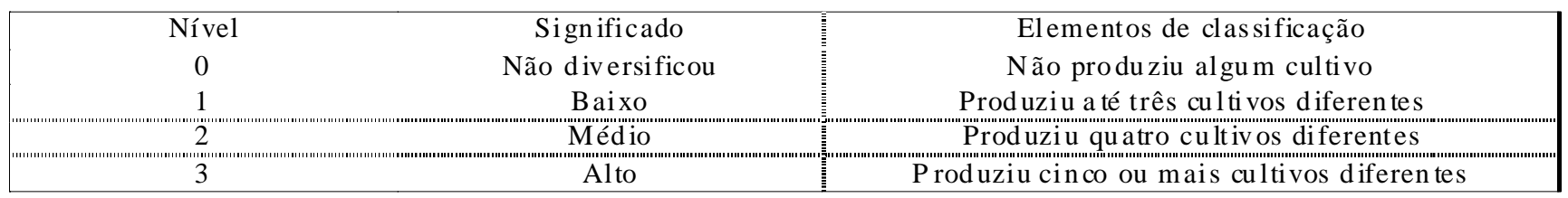


Tabela 13 - Nível de diversificação hortícola por região de estudo nas Zonas Verdes.

\begin{tabular}{|c|c|c|c|c|c|c|c|c|}
\hline \multirow[t]{2}{*}{ Local } & \multicolumn{2}{|c|}{ Não di versificou } & \multicolumn{2}{|c|}{ Baixo } & \multicolumn{2}{|c|}{ Médio } & \multicolumn{2}{|c|}{ Alto } \\
\hline & Número & $\begin{array}{c}\% \text { no } \\
\text { intervalo }\end{array}$ & Número & $\begin{array}{c}\% \text { no } \\
\text { intervalo }\end{array}$ & Número & $\begin{array}{c}\% \text { no } \\
\text { intervalo }\end{array}$ & Número & $\begin{array}{c}\% \text { no } \\
\text { intervalo }\end{array}$ \\
\hline Mahotas & 9 & 20,5 & 13 & 29,5 & 10 & 22,7 & 12 & 27,3 \\
\hline Vale do Infulene & 5 & 20,8 & 7 & 29,2 & 11 & 45,8 & 1 & 4,2 \\
\hline Total & 14 & 20,6 & 20 & 29,4 & 21 & 30,9 & 13 & 19,1 \\
\hline
\end{tabular}

Fonte: Dados de pesquisa.

A aparente falta ou baixo nível de diversificação esteve ligado aos seguintes fatores:

1. O medo de roubo de cultivos nas machambas: os produtores associam os roubos à falta de empregos; a solução dos roubos ultrapassa a capacidade dos produtores, que consideram ser necessária a intervenção do governo.

"A contratação de guardas para a proteção das suas machambas contra o roubo não é viável, uma vez que é grande o número de pequenas machambas. Se o governo nos instalasse um posto policial aqui perto os ladrões teriam medo, pois saberiam da presença da polícia no local" (Entrevista com os produtores da Associação Joaquim Chissano, nas Mahotas).

2. O receio de que os cultivos sejam arrastados pela água da chuva (enchentes): nos dois locais de estudo (Mahotas e vale do Infulene), os problemas da água têm características diferentes: nas Mahotas os produtores se queixam da falta de sistemas de irrigação - para não depender apenas da água chuva, que é escassa na época seca. No Vale do Infulene, as preocupações da água estão ligadas às inundações dos cultivos durante a época chuvosa.

3. O menor tamanho das machambas, como sugere a colocação seguinte:

"Não diversifiquei a produção porque a minha machamba é pequena" (Francisco Simon Menezes, Associação Joaquim Chissano).

4. A falta de equipamentos de processamento (principalmente de frio para acondicionar as hortícolas);

5. O deficiente estado das vias de acesso para o escoamento da produção;

6. A falta de sementes de qualidade; $\mathrm{e}$

7. A falta de mercado - termo usado de forma recorrente pelos produtores para se referirem principalmente à sua incapacidade de negociar os preços dos produtos junto das maguevas ${ }^{15}$. A colocação seguinte evidencia essa dificuldade dos produtores:

"[...] Quando a magueva chega, ela marca o seu preço e a produtora não tendo mais nada para cozinhar, entrega o canteiro a qualquer preço"

\footnotetext{
${ }^{15}$ Termo usado localmente para designar os comerciantes (geralmente mulheres) que se dedicam a compra no varejo dos produtos nas machambas, posteriormente revendidos nos mercados da cidade.
} 
(Entrevista com a Diretora da Agricultura do Distrito 5).

Além dos motivos acima expostos, observou-se que existe certo receio dos produtores em embarcar em cultivos diferentes dos habituais. A rápida rotatividade dos cultivos habituais (a couve e alface) contribui para esse receio em relação à mudança. Por outro lado, observou-se que para os "pequenos produtores" a possibilidade de diversificação está ligada ao bem-estar social - em geral os produtores "pobres" não diversificam a sua produção, limitando-se a produzir apenas alguns cultivos para o consumo familiar. Nessa categoria de produtores "pobres" geralmente se encontram as mulheres viúvas e aquelas que, por situação de saúde, não conseguem trabalhar convenientemente as suas parcelas ou que não têm machambas próprias.
Por outro lado, no que diz respeito à diversificação produtiva, podem atribuir-se as diferenças ao diverso capital social das duas regiões, principalmente em termos da atuação das associações de produtores, quantidade de ONGs e assistência técnica. Nas Mahotas, se observou que as associações de produtores são mais ativas do que no Vale do Infulene; nas Mahotas, três ONGs estão presentes: (i) a Iscos, que trabalha na sensibilização sobre HIV/Aids e microcrédito; (ii) a Kulima, que trabalha no apoio à legalização das associações de produtores; e (iii) a ADPP, que trabalha na distribuição gratuita de sementes, construção de poços artesanais e fomento de animais de pequena espécie (porcos, patos e galinhas). Neste local (Mahotas), cerca de $40 \%$ dos produtores afirmaram ter recebido assistência técnica, enquanto no Vale do Infulene, esse índice foi de apenas $28 \%$ (Tabela 14).

Tabela 14 -Assistência técnica, número e percentagem de produtores assistidos por região.

\begin{tabular}{|c|c|c|c|c|c|c|}
\hline \multirow[t]{2}{*}{ Local } & \multicolumn{4}{|c|}{ Recebeu assistência } & \multicolumn{2}{|r|}{ Total } \\
\hline & Número & $\begin{array}{l}\text { Sim } \\
\text { Percentagem } \\
\quad(\%)\end{array}$ & Número & $\begin{array}{l}\text { Não } \\
\text { Percentagem } \\
\qquad(\%)\end{array}$ & Número & $\begin{array}{c}\text { Percentagem } \\
(\%)\end{array}$ \\
\hline Mahotas & 28 & 41,18 & 16 & 23,53 & 44 & 64,71 \\
\hline Vale do Infulene & 19 & 27,94 & 5 & 7,35 & 24 & 35,29 \\
\hline Total & 47 & 69,12 & 21 & 30,88 & 68 & 100,00 \\
\hline
\end{tabular}

Fonte: Dados de pesquisa.

No total, cerca de $70 \%$ dos produtores receberam assistência técnica nos dois locais - Mahotas e Vale do Infulene. A metodologia de "Escolas na Machamba do Camponês" que está sendo usada pelos técnicos dos serviços públicos de extensão rural incorpora princípios de aprendizagem informal e utiliza poucos recursos enquanto permite atingir maior número de produtores assistidos. No entanto, alguns produtores entrevistados no Infulene referiram que é difícil implementar as mensagens ensinadas pelos agentes de extensão:

"(...) dizem para semearmos em linhas, é difícil; por isso, quando eles vão embora nós ficamos a semear à nossa maneira" (Entrevistada na associação Marcelina Chissano de Zimpeto). 
SITOE, T.A.

Por outro lado, embora os produtores tenham contato com o extensionista na "Escola na Machamba do Camponês", este dificilmente tem condições de visitar todos os produtores sob sua áreade trabalho (assistência) e ver se, na prática, os produtores estão levando a cabo os ensinamentos da "Escola na Machamba do Camponês", conforme sugere a afirmação seguinte ${ }^{16}$ :

"Eu só o vejo aqui na machamba da associação; na minha machamba nunca o vi (Entrevista 32, 22/11/2009)
A renda média dos produtores que receberam assistência técnica foi cerca de 59.000 Meticais, enquanto a dos produtores que não receberam assistência foi de cerca de 40.000 Meticais. No entanto, a $5 \%$ de significância não existem diferenças significativas entre esses valores, o que mostra que a assistência técnica ainda não se traduz em efeito relevante na renda dos produtores (Tabelas 15 e 16). Por outro lado, a assistência técnica explica apenas $2 \%$ das variações na renda hortícola (Tabela 17).

Tabela 15 - Assistência técnica, média de renda hortícola entre produtores assistidos e não assistidos.

\begin{tabular}{lccc} 
Recebeu assistência & Média & Número & Desvio Padrão \\
\hline Sim & $59.047,04$ & 47 & 68415,589 \\
Não & $39.664,62$ & 21 & 40466,480 \\
Total & $53.061,29$ & 68 & 61512,703 \\
\hline
\end{tabular}

Fonte: Dados de pesquisa.

Tabela 16 - Análise de variância (Anova) entre a renda hortícola dos produtores assistidos e não assistidos.

\begin{tabular}{cccccc}
\hline & $\begin{array}{c}\text { Soma dos } \\
\text { quadrados }\end{array}$ & $\begin{array}{c}\text { Graus de } \\
\text { liberdade }\end{array}$ & $\begin{array}{c}\text { Quadrado } \\
\text { médio }\end{array}$ & F & $\begin{array}{c}\text { Nível de } \\
\text { Significância. }\end{array}$ \\
\hline Entre grupos & $5 \mathrm{E}+009$ & 1 & 5452860625 & 1,4551 & 0,233 \\
Dentro dos grupos & $2 \mathrm{E}+011$ & 66 & 3758524076 & & \\
Total & & 67 & & & \\
\hline
\end{tabular}

Fonte: Dados de pesquisa.

Tabela 17 - Medidas de associação entre a renda hortícola e a assistência técnica.

\begin{tabular}{lcc}
\hline & Eta & Eta Squared \\
\hline Renda hortícola * Recebeu assistência & 0,147 & 0,022 \\
\hline
\end{tabular}

Fonte: Dados de pesquisa.

\footnotetext{
${ }^{16} \mathrm{~A}$ machamba da associação refere-se à "Escola na Machamba do Camponês", onde acontece o treinamento (as práticas).
} 


\section{Considerações Finais}

A diversificação hortícola teve pouco efeito sobre a renda (as diferenças de média só são significativas acima de 5,6\%). No entanto, estudos realizados em outros contextos indicam que a diversificação produtiva tem sido considerada uma das estratégias essenciais para o aumento de renda e redução da pobreza (DHARMASIRI, 2007; GIOÈ, 2000).

O teste estatístico realizado para comparar as médias de renda dos produtores não fornece evidências suficientes para a 5\% de significância rejeitar a hipótese de igualdade entre a renda dos produtores diversificados e a dos não diversificados. No entanto, é temeroso afirmar que a esse nível as diferenças não são significativas, uma vez que o valor de $p$-value foi 0,056 (apenas é 0,006 unidades maior que 0,050 nível de significância adotado nas análises). Até porque a renda média hortícola dos produtores diversificados foi de cerca de 61.000 Meticais e a renda média hortícola dos produtores que não diversificaram foi de 27.000 Meticais; pode-se afirmar que se está perante uma situação em que os fatos podem não apresentar evidência suficiente para condenar um arguido. Podemos considerar que as médias anteriores passam a ser diferentes a $6 \%$ ou mais. Adistribuição assimétrica é causa mais provável para que valores aparentemente distintos não tenham resultado em diferenças significativas ${ }^{17}$.

Apesar disso, a importância da diversificação não é apenas avaliada em termos do teste Anova, uma vez que os produtores atribuem um sentido positivo à diversificação da produção para o aumento da sua renda. No entanto, os produtores poderiam diversificar se houvesse algum apoio, principalmente do Estado. Dentro das associações falta ainda a capacidade de buscar soluções a partir do esforço dos próprios produtores. Estes veem no governo a figura que deve ajudar a resolver os problemas que enfrentam. Alguns problemas exigem de fato a intervenção do Estado para que crie incentivos e políticas que estimulem o desenvolvimento da atividade agrícola; no entanto, a atitude dos produtores pode refletir, por um outro lado, o vício das intervenções massivas realizadas pelo Estado no passado; mas também a consciência dos produtores em relação ao clientelismo que atualmente caracteriza a ação do Estado em relação às associações. Algumas questões que se colocam e carecem de aprofundamento são, por exemplo: o projeto do governo em relação às associações é excludente? Será que os privados têm de fato autonomia? Por que esses produtores são poucos nas associações? Como é que o apoio do Estado pode ser mais bem direcionado a criar mudanças no bemestar dos produtores e seus familiares?

A análise do impacto da extensão rural geralmente se faz pela contagem do número de pessoas assistidas; poucos estudos tratam de avaliar o impacto da assistência em termos de renda dos produtores, o que dificulta a comparação dos resultados da pesquisa com outros trabalhos. No entanto, o fato de que $70 \%$ dos produtores teve assistência técnica e não produziu diferenças significativas em termos de renda, em comparação com os não assistidos, indica que provavelmente as tecnologias usadas ou o método das "Escola na Machamba do Camponês" não estão a produzir efeitos substanciais no bem-estar das famílias. Os serviços de extensão agrícola enfrentam uma série de dificuldades: (a) a falta de meios de transporte para os técnicos; (b) insuficiência de técnicos; (c) baixa qualificação acadêmica dos técnicos; (d) falta de incentivos, etc.

A extensão poderia ajudar os produtores a melhorar

\footnotetext{
${ }^{17}$ Foi efetuada uma transformação da variável renda em seu logaritmo natural; no entanto, as diferenças entre a média e a mediana permaneciam maiores. Convém salientar que muitos testes estatísticos exigem a normalidade. Apesar da sua violação pouco afetar a inferência sobre os valores médios, pode ter efeito considerável nas inferências sobre variâncias, nomeadamente quando se trata distribuição "mesocúrticas". A assimetria na distribuição de frequências da renda é também confirmada pelo quociente entre ?Skewness/StdError ? = 11,57, que é maior que 1,96. Isso significa que a mediana não pertence ao intervalo de confiança.
} 
a sua renda através da diversificação produtiva. O nível de diversificação produtiva ainda é baixo, como atesta o fato de que 16 produtores não diversificaram e tiveram uma renda aparentemente igual à de 52 que diversificaram.

A extensão agrícola pode ajudar os produtores a melhorar a produtividade das suas terras e, com isso, gerar a renda necessária à sua sobrevivência. No entanto, a forma como os produtores usam a informação relacionada com variedades melhoradas e gestão de recursos depende da efetividade dos serviços de extensão e outros meios de comunicação e o nível de educação dos produtores (HEISEY \& BYERLEE, 1993, p. 29). Para isso, é necessário que esse apoio seja completado pela melhora no acesso ao crédito, apoio à comercialização, segurança nas machambas, investimentos em infraestruturas, etc.

\section{Agradecimentos}

Agradeço especialmente ao prof. dr. Waquil pela assistência na análise dos dados; aos professores Jalcione Mileitz, pelos comentários, e Carlos Adalberto Mielitz, pela orientação. Ao Júlio Feio Langa pelo apoio na análise de consistência dos dados e ao Hugo Mabilane pelo programa SPSS.

\section{Referências}

ANTHOLT, Charles. Agricultural Extension in the Twenty-first Century. In: CARL, Eicher; John, Staatz (Ed.). International Agricultural

Development. 3.ed. Baltimore: Johns Hopkins University Press., 1998. p. 354-369.

BRAUN, Arnoud; DUVESKOG, Deborah. The Farmer Field School Approach - History, Global Assessment and Success Stories.

Unedited draft. Disponível em http://ifad.org/rural/ rpr2008/chapter3/3.pdf . Acesso em: 27 agosto 2010.

CLEAVER, Kevin. Making Agricultural Extension Work in Africa. In: In: RUSSELL, Nathan C.;
DOWSWELL, Christopher R. (Eds.). Policy Options for Agricultural Development in SubSaharan Africa. Mexico: CASIN/SAA/Global 2000, 1993

\section{CHAMBERS, Robert. Whose Reality Counts?;} Putting the Last First. London: Intermediate Technology Publications, 1997.

\section{DHARMASIRI, Lal Mervin R.K. Multiple Crop} Diversification and Intensification; A Case

Study of Sri Lanka. International Conference on Agribusiness and Food Industry in Developing Countries; Opportunities and Challenges, 10-12 de agosto de 2007. Disponível em: http://

www.iiml.ac.in/events/

C17_02_Lal_Mervin_Dharmasiri.pdfAcesso em: 25 agosto 2010.

DAVIS, Kristian. Farmer Field School: ABoon or Bust for Extension in Africa? Addis Ababa, Ethiopia: International Food Policy Research Institute, 2006.

DZECO, César; AMILAI, Castilho; CRISTOVÃO, Artur. Farm field schools and farmer's

empowerment in Mozambique: A pilot study. 9th European IFSA Symposium, 4?7 July 2010, Vienna (Austria). Disponívelem http://ifsa.boku.ac.at/cms/ fileadmin/Proceeding2010/2010_WS1.1_Dzeco.pdf Acesso em: 25 agosto 2010.

\section{ELLIS, Frank. Rural livelihood and} diversification in developing countries. Oxford: University Press, july 2000.

\section{FOOD AND AGRICULTURE ORGANIZATION OF THE UNITED NATIONS (FAO). Guia de} Formação para a Extensão. Roma: FAO, 1992.

GIOÈ, Mauro. Can Horticulture Production Help African Smalholders to Escape Dependence on Export of Tropical Agricultural Commodities? Crossroads, vol.6, n 2. pp.16-65, 2006. 
Disponível em http://webasa.org/publicazion/

Gioe_2006_pdf. Acesso em: 25 março de 2009.

GOVERNO DE MOÇAMBIQUE (GdM). Plano de Ação para Redução da Pobreza Absoluta, 2006-2009 (PARPA II). Versão final aprovada pelo Conselho de Ministros, Maputo, Maio de 2006.

HEISEY, Paul; BYERLEE, Derek. Strategies for Technical Change in Small-Farm Agriculture, With Particular Reference to Sub-Saharan Africa. In: RUSSELL, Nathan C.; DOWSWELL, Christopher R. (eds.). Policy Options for Agricultural Development in Sub-Saharan Africa. Mexico, CASIN/SAA/Global 2000, 1993.

\section{KOREA INSTITUTE FOR DEVELOPMENT} STRATEGY- KDS. Building the Basics for Innovation of Agricultural Productivity in Mozambique. Korea: Ministry of Strategy and Finance, 2009.

\section{MINISTÉRIO DAAGRICULTURA(MINAG). Extension Master Plan 2007-2016. Final Draft. Maputo: MINAG, out. 2006.}

O' CATHAIN, Alicia; THOMAS, Kate.

Combinando métodos qualitativos e quantitativos. In: POPE, Catherine; Mays, Nicholas. Pesquisa qualitativa na atenção à saúde. Tradução Ananyr Porto Forjado. 3.ed. Porto Alegre: Artmed, 2009.

OLIVEIRA, Valter L. Liberdade e Poder em Amatya Sen: uma leitura crítica. Desenvolvimento em Questão. Unijuí, v.5, n. 9, Jan./Jun., 2007.
ROSÁRIO, Carmeliza; TVEDTEN Inge; PAULO, Margarida. Relações Sociais da Pobreza Rural Urbana no Centro de Moçambique. Direção Nacional de Estudos e Análise de políticas: Discussion papers, n. 63p. agosto de 2009.

SEN, Amartya. Poor, relatively speaking. Oxford Economic Papers, v.35, n.2, p. 153-169., 1983.

Editorial: Human capital and Human capability. World Development, v. 25, n. 12, p. 1959-191, 1997.

SCARBOROUGH, Vanessa; KILLOUGH, Scott; JOHNSON, Debra; FARRINGTON, John. Farmerled-Extension: Concepts and Practices. London: Intermediate Technology Publications, 1997.

SINGH, Yogendra K. PAN II e Escola na Machamba do Camponês, in FAOnews. Disponível em: http://www.foodsec.org/docs/ 1_release_FAO_Bulletin_Janeiro.pdf, August 30th, 2008.

TVEDTEN, Inge; PAULO Margarida; MONTSERRAT Georgina. Gender Policies and Feminisation of Poverty in Mozambique. Norway: Chr. Michelsen Institute, 2008.

TIFFEN, Mary; MORTIMORE, Michael; GICHUKI, Francis. More People, Less Erosion;Environmental Recovery in Kenya. Wiley and Sons, Chichester, John Wiley, 1994

RECEBIDO EM 8/11/2010

ACEITO EM 14/12/2010 